\title{
Detection of adsorbed explosive molecules using thermal response of suspended microfabricated bridges
}

Yi, Dechang; Greve, Anders; Hales, Jan Harry; Senesac, Larry R.; Davis, Zachary James; Nicholson, Don M.; Boisen, Anja; Thundat, Thomas

Published in:

Applied Physics Letters

Link to article, DOI:

$10.1063 / 1.3002285$

Publication date:

2008

Document Version

Publisher's PDF, also known as Version of record

Link back to DTU Orbit

Citation $(A P A)$ :

Yi, D., Greve, A., Hales, J. H., Senesac, L. R., Davis, Z. J., Nicholson, D. M., Boisen, A., \& Thundat, T. (2008). Detection of adsorbed explosive molecules using thermal response of suspended microfabricated bridges. Applied Physics Letters, 93(15), 154102. https://doi.org/10.1063/1.3002285

\section{General rights}

Copyright and moral rights for the publications made accessible in the public portal are retained by the authors and/or other copyright owners and it is a condition of accessing publications that users recognise and abide by the legal requirements associated with these rights.

- Users may download and print one copy of any publication from the public portal for the purpose of private study or research.

- You may not further distribute the material or use it for any profit-making activity or commercial gain

- You may freely distribute the URL identifying the publication in the public portal 


\title{
Detection of adsorbed explosive molecules using thermal response of suspended microfabricated bridges
}

\author{
Dechang Yi, ${ }^{1}$ Anders Greve, ${ }^{2}$ Jan H. Hales, ${ }^{2}$ Larry R. Senesac, ${ }^{1,3}$ Zachary J. Davis, ${ }^{2}$ \\ Don M. Nicholson, ${ }^{1}$ Anja Boisen, ${ }^{2}$ and Thomas Thundat ${ }^{1,3, a)}$ \\ ${ }^{1}$ Biosciences Division, Oak Ridge National Laboratory, Oak Ridge, Tennessee 37831, USA \\ ${ }^{2}$ MIC, Technical University of Denmark, Lyngby DK-2800, Denmark \\ ${ }^{3}$ Department of Physics, University of Tennessee, Knoxville, Tennessee 37996, USA
}

(Received 26 August 2008; accepted 28 September 2008; published online 16 October 2008)

\begin{abstract}
Here we present a thermophysical technique that is capable of differentiating vapor phase adsorbed explosives from nonexplosives and is additionally capable of differentiating individual species of common explosive vapors. This technique utilizes pairs of suspended microfabricated silicon bridges that can be heated in a controlled fashion. The differential thermal response of the bridges with and without adsorbed explosive vapor shows unique and reproducible characteristics depending on the nature of the adsorbed explosives. The tunable heating rate method described here is capable of providing unique signals for subnanogram quantities of adsorbed explosives within 50 ms. (C) 2008 American Institute of Physics. [DOI: 10.1063/1.3002285]
\end{abstract}

Despite its immediate relevance in homeland security applications, high sensitivity detection of explosives using real-time, miniature sensors still remains as a crucial challenge. ${ }^{1-3}$ Although it is the most widely used method and is highly effective, trace explosive detection based on canines is neither cost effective nor suitable for mass deployment. ${ }^{4,5}$ Currently available trace detection technologies, such as ion mobility spectrometry ${ }^{6}$ are bulky and expensive. Optical spectroscopic techniques such as Raman and laser-induced breakdown spectroscopies are highly selective but suffer from poor sensitivity. ${ }^{7}$ Micro-electromechanical systems (MEMS) can potentially satisfy many of the requirements for an ideal compact chemical sensor such as low-power consumption, real-time operation, and high sensitivity. Currently MEMS are considered as a potential platform for the development of next generation vapor sensors. However, the suitability of MEMS as practical sensors for vapor detection has been limited by lack of chemical selectivity.

The selectivity challenge encountered with micromechanical sensors is not unique to MEMS. Other gravimetric sensors such as quartz crystal microbalance ${ }^{8}$ and surface acoustic wave ${ }^{9}$ devices also lack intrinsic selectivity and rely on selective interfaces ${ }^{10}$ for chemical speciation. The need for chemical selectivity forces the use of separation techniques or the use of highly selective recognition layers that are irreversible at room temperature. Although attractive from an analytical standpoint, incorporation of separation techniques with MEMS sensors poses integration problems, especially for explosives detection due to the large volumes of air needed for sample collection.

Approaches for achieving selectivity by using sensor arrays modified with partially selective, reversible interfaces, and pattern recognition work are presently underway. ${ }^{11-15}$ The molecular recognition interfaces that are based on weak interactions are not specific enough to produce unique responses with a single sensor. Unique responses (orthogonal) cannot be obtained if the mechanism behind individual sen-

\footnotetext{
a) Author to whom correspondence should be addressed. Electronic mail: thundattg@onrl.gov.
}

sor elements is unspecific, for example, hydrogen bonding of analyte with the chemoselective layer. Increasing the number of sensor elements in the array for pattern recognition analysis can improve the selectivity only if the responses from individual sensing elements are orthogonal. However, there are only a limited number of weak reversible chemical interactions that can serve as a basis for designing the selective layers. Therefore, despite all the chemical sensing advantages offered by microfabricated sensors, their use as a practical sensor requires more work toward developing techniques that can generate orthogonal responses.

In this letter, we demonstrate a technique that is based on thermal response of explosives adsorbed on a suspended bridge that can be electrically heated to a high temperature. This physical response can provide an orthogonal signal to those produced by partially selective chemical adsorption based techniques. This method, which utilizes one of the most underexploited properties of MEMS sensors, namely, their extremely low thermal mass, is compatible with batch fabrication. The extreme low thermal mass of MEMS allows controllable sensor heating rates, $d T / d t$, where $T$ is the temperature and $t$ is the time, of up to $10^{8}{ }^{\circ} \mathrm{C} / \mathrm{s} .{ }^{16}$ This tunable heating suspend bridge technique is similar to that of temperature programmed desorption but carried out at a higher $d T / d t$. The temperature of a suspended bridge with surface adsorbed explosives when heated as a function of time show unique patterns due to thermal characteristics of the adsorbed material.

Figure 1 shows electron micrograph of a suspended bridge that can be heated to a few hundred degrees in less than a millisecond. Each suspended bridge is microfabricated from silicon-on-insulator wafers and has three buried electrically conducting tracks with all tracks separated by thin layers of insulating silicon rich nitride. Out of the three buried conducting tracks on each bridge, the one in the middle is used as a resistive temperature-measuring strip while the other two tracks are used for heating the bridge by passing current through them. Further details regarding bridge fabrication will be published elsewhere. When the bridge is heated by passing an electrical current through the outermost tracks, the resistance of the internal track varies sensitively 


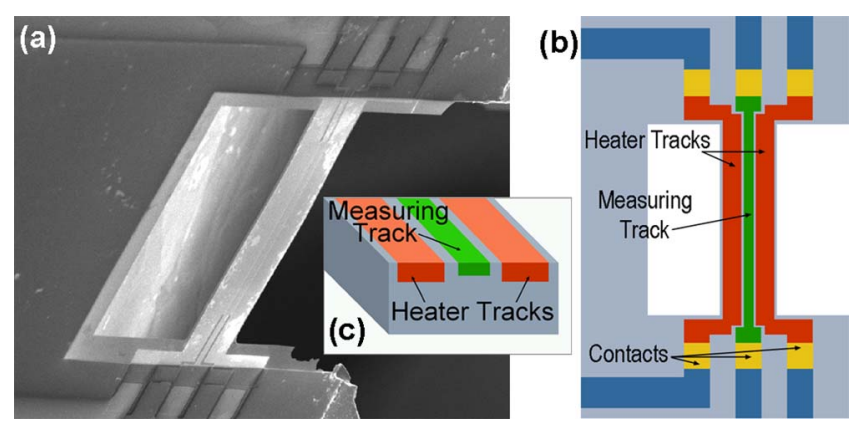

FIG. 1. (Color online) (a) An SEM image of a microfabricated silicon bridge structure with dimensions of $450 \mu \mathrm{m}$ in length, $100 \mu \mathrm{m}$ in width, and $550 \mathrm{~nm}$ in thickness. Imbedded in the bridge are two heater tracks, one on either side of a resistive temperature measuring track in the middle as shown in (b) and (c).

as a function of bridge temperature. Since the rate of heating depends on the mass of the bridge, a bridge with added mass (adsorbed mass) will have a different rate of heating compared to a bare bridge. At the end of the heat cycling all the adsorbed mass desorbs from the surface and the response returns to the baseline signal as that of the bridge with no adsorbed mass. The resistances of the sensor bridge and reference bridge were measured using a Wheatstone bridge circuit.

The experimental arrangement involves two identical bridges where one serves as the reference for common mode rejection (protected from explosive vapor adsorption). The differential rate of change in temperature of the bridge, measured as resistance variation, is proportional to the rate of change in thermal mass of the sensor bridge due to thermal desorption of the adsorbed molecules $(d M / d T)$. Therefore, the thermal response of a bridge with adsorbed mass is expected to be different from the reference bridge due to additional thermal mass.

Three explosives were chosen for our experiments: cyclotrimethylenetrinitromine (RDX) trinitrotoluene (TNT), and pentaerythritol tetranitrate (PETN). We have used a custom-made vapor generator with heated outlet to deliver explosive vapors at selected concentrations onto the sensor bridge. The details of the vapor generators can be found elsewhere. ${ }^{17}$ In the explosive vapor generator, the explosive vapors were created by a higher temperature heating process, and therefore, they condense on the sensor bridge, which was maintained at room temperature. All the vapor depositions were carried out in open air. Therefore, the sensor bridge is exposed to room humidity and other ambient vapors. The mass of adsorbed explosive vapor was calculated using a resonating microcantilever beam placed in the same plane as the bridge chip. ${ }^{18}$ It should be noted that since the explosive adsorption is carried out in an open environment, only a fraction of the explosive vapor is deposited on the bridge.

Figure 2 shows the thermal response of a TNT covered bridge (differential variation in resistance with respect to a reference bridge) plotted on the $y$-axis as a function of heating time on the $x$-axis when heated with a square wave pulse. The temperature of the bridge rises from room temperature to approximately $550{ }^{\circ} \mathrm{C}$ in the first $50 \mu$ s of the pulse and is held there for $10 \mathrm{~ms}$. The response curve appears to be Gaussian with no special features. Similar Gaussian responses were also observed for fast heating of other explosives as well as nonexplosives. The observed responses are

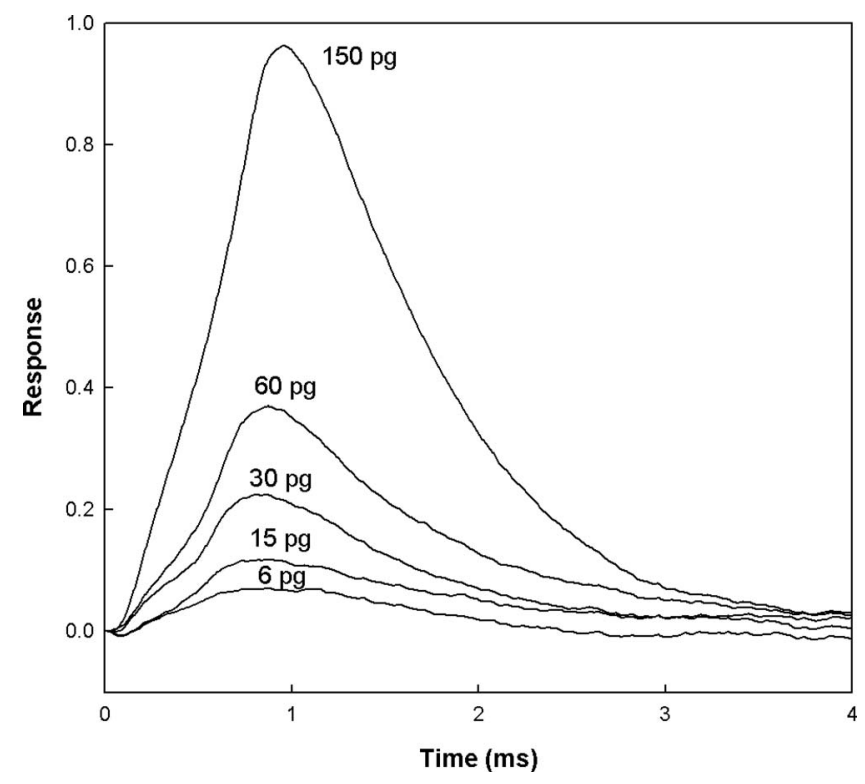

FIG. 2. Thermal responses of a bridge with adsorbed TNT under fast, square wave pulse heating with a $d T / d t$ value of $10^{7}{ }^{\circ} \mathrm{C} / \mathrm{s}$. For this fast heating method, the shape of the response looked the same for all materials tested. The material desorbs in less than $5 \mathrm{~ms}$. The response shown is the Wheatstone bridge voltage indicating the resistance difference $R_{\text {(reference Bridge) }}$ $-R_{(\text {Loaded Bridge) }}$.

consistent with desorption of the adsorbed material from the bridge. The mass loss due to desorption resembles a sigmoid function and the rate of desorption resembles a Gaussian peak. ${ }^{19}$

However, drastically different response curves are obtained when analyte covered bridges are heated using a voltage ramp. A too fast heating rate results in Gaussian peaks while a too slow heating rate results in broadened peaks due to slow evaporation. We have experimentally determined that for a $d T / d t$ value of $1.1 \times 10^{4}{ }^{\circ} \mathrm{C} / \mathrm{s}$, the thermal responses showed unique signatures for each explosive. Figure 3 shows bridge response obtained with three different types of explosives (TNT, RDX, and PETN) and two nonexplosives. Each explosive can be distinguished using the shape of the temperature response. The three separate line curves plotted for each explosive in Fig. 3(a) correspond to three separate experiments with varying amounts of explosive. Notice that the amplitude of the response varies as a function of the mass of adsorbed explosive, but the shape of the response remains constant for a given explosive. Unlike the response from fast heating, which fails to provide an analyte dependent uniqueness, varying the temperature with a temporal gradient shows unique responses. The response may be due to a combination of the thermal characteristics such as melting, evaporation, sublimation, and deflagration. We have obtained a limit of detection of $600 \mathrm{pg}$ using our present arrangement. Figure 3(b) shows the responses from two nonexplosive materials adsorbed on the bridge surface [ammonium chloride $\left(\mathrm{NH}_{4} \mathrm{Cl}\right)$ and sodium borate $\left.\left(\mathrm{Na}_{2} \mathrm{~B}_{4} \mathrm{O}_{7}\right)\right]$. The responses from the adsorbed nonexplosives resemble Gaussian peaks devoid of any features, which is consistent with desorption.

We have carried out similar experiments for a limited number of volatile organic compounds (VOCs) (such as acetone, acetonitrile, and methanol) and ambient humidity (20\%-65\%), which showed no observable thermal responses. It may be possible that the amount of VOCs adsorbed on the bridge may have been much lower compared 
(a)

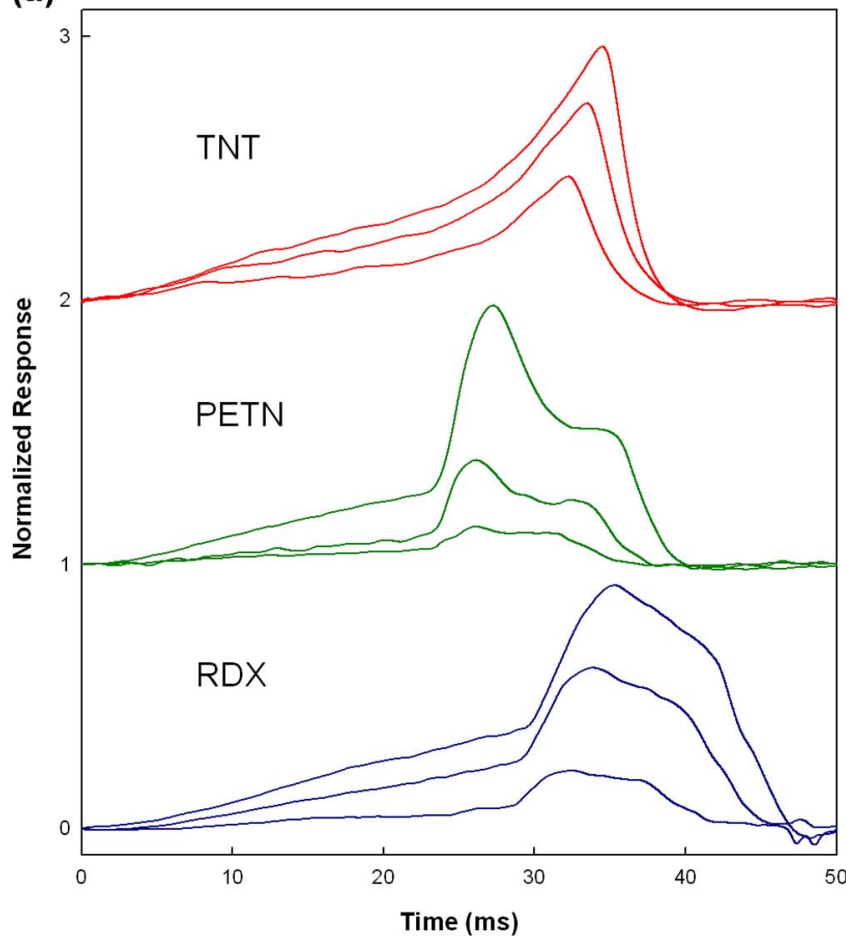

(b)

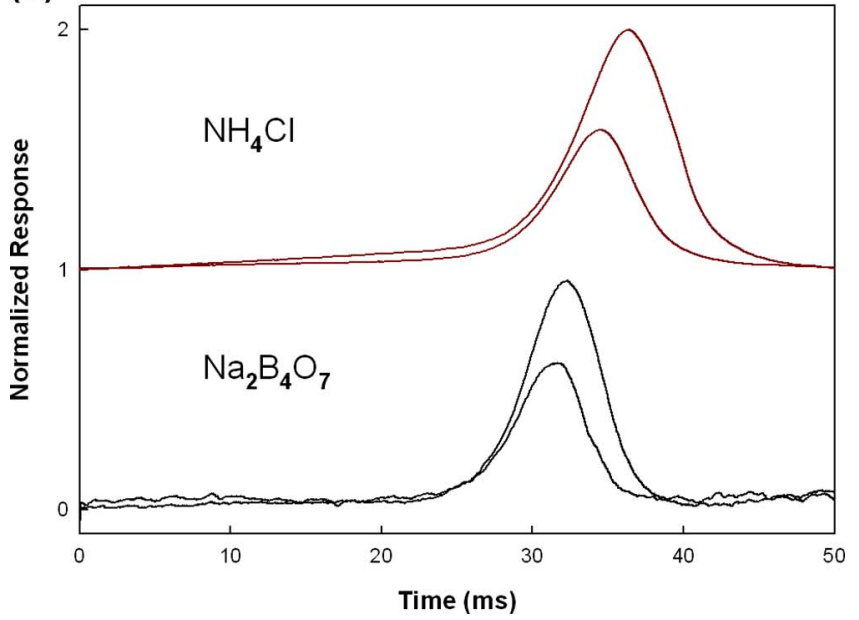

FIG. 3. (Color online) Thermal response signatures of explosives and nonexplosives. (a) Thermal response of a bridge with adsorbed explosive molecules. Sensor output is plotted as a function of time ( $x$-axis) due to application of a linear heating voltage ramp ( 0 to $5.4 \mathrm{~V}$ in $50 \mathrm{~ms}$ ) with an average $d T / d t$ of $10^{4}{ }^{\circ} \mathrm{C} / \mathrm{s}$. The response change in temperature is measured from changes in bridge resistance with respect to a reference bridge such that a positive signal indicates that the temperature of the reference bridge is higher than that of the analyte loaded bridge $R_{\text {(reference Bridge) }}-R_{\text {(Loaded Bridge) }}$. Shown are the detector responses for three explosive species. The three different curves shown for each analyte represent $0.6,1.2$, and $2.4 \mathrm{ng}$ of adsorbed explosive on the device and are normalized to make each $2.4 \mathrm{ng}$ response have unit amplitude. (b) Thermal response of a bridge with adsorbed nonexplosive molecules carried out with the same $d T / d t$ as for the explosives. The thermal spectrum for nonexplosives shows a Gaussian response with peak value changing with the amount of adsorbate. Unlike the thermal spectrum for explosives, the nonexplosive spectrums are featureless.

to that of explosives due to their high vapor pressures at ambient temperature. Mixtures of explosive and solvent, such as acetone and acetonitrile (as determined with gas chromatography-mass spectrometry measurements), also results in explosives response peaks similar to that of pure material indicating that the solvents do not condense on the bridge at room temperature.
Obtaining selective responses in trace explosive vapor detection using thermally induced properties of adsorbed molecules offers a simple method for chemical sensing. This detection method, which is free of any chemoselective layers, offers high sensitivity and selectivity and overcomes the most fundamental disadvantages of previous MEMS and NEMS (nano-electro-mechanical systems) sensors. The sensitivity beyond what is demonstrated will be possible by micromachining bridges with decreased thermal mass and optimized surface area. Perhaps the most important advantage of the method is that the detection process can be repeated continuously with the sensor regenerating to a pristine surface after each thermal cycle without resorting to chemical cleaning techniques. This was confirmed by atomic force microscopy and optical imaging and by hundreds of measurements repeated on dozens of the different bridge devices all giving the same reproducible response shapes for the analytes tested.

In conclusion we have demonstrated a temperaturebased technique for obtaining unique signals for adsorbed explosives. The demonstrated sensitivity and selectivity of this approach offer possibilities for a single sensor-based technique that does not use a chemoselective layer for sensing. This method may also be used in parallel with a chemoselective layer based technique in a MEMS array providing orthogonal signals for pattern recognition. These micromachined devices have the obvious advantages of requiring subnanogram samples, fast detection time, simplicity, and the potential for low cost.

We thank Dr. Richard Lareau and Dr. Eric Houser for discussions on explosive detection. This research was supported in part by U.S. Department of Homeland Security and the Office of Naval Research. ORNL is managed by UTBattelle and LLC for the U.S. Department of Energy under Contract No. DE-AC05-00OR22725.

${ }^{1}$ R. J. Colton and J. N. Russell, Science 299, 1324 (2003).

${ }^{2}$ S. F. Hallowell, Talanta 54, 447 (2001).

${ }^{3}$ A. Fainberg, Science 255, 1531 (1992).

${ }^{4}$ R. J. Harper and K. G. Furton, Counterterrorist Detection Techniques of Explosives, edited by J. Yinon (Elsevier, New York, 2007).

${ }^{5}$ J. Yinon, Anal. Chem. 75, 99A (2003).

${ }^{6}$ H. H. Hill and G. Simpson, Field Anal. Chem. Technol. 1, 119 (1997).

${ }^{7}$ S. K. Sharma, A. K. Misra, and B. Sharma, Spectrochim. Acta, Part A 61, 2404 (2005)

${ }^{8}$ G. Bunte, J. Hurttlen, H. Pontius, K. Hartlieb, and H. Krause, Anal. Chim. Acta 591, 49 (2007).

${ }^{9}$ E. J. Houser, T. E. Mlsna, V. K. Nguyen, R. Chung, R. L. Mowery, and R. A. McGill, Talanta 54, 469 (2001)

${ }^{10}$ L. A. Pinnaduwage, V. Boiadjiev, J. E. Hawk, and T. Thundat, Appl. Phys. Lett. 83, 1471 (2003).

${ }^{11}$ M. D. Hsieh and E. T. Zellers, Anal. Chem. 76, 1885 (2004).

${ }^{12}$ D. R. Walt, Anal. Chem. 77, 45A (2005).

${ }^{13}$ C. J. Lu, J. Whiting, R. D. Sacks, and E. T. Zellers, Anal. Chem. 75, 1400 (2003).

${ }^{14}$ L. R. Senesac, P. Dutta, P. G. Datskos, and M. J. Sepaniak, Anal. Chim. Acta 558, 94 (2006).

${ }^{15}$ J. W. Jaworski, D. Raorane, J. H. Huh, A. Majumdar, and S. W. Lee Langmuir 24, 4938 (2008).

${ }^{16}$ J. Lee, T. Beechem, T. L. Wright, B. A. Nelson, S. Graham, and W. P. King, J. Microelectromech. Syst. 15, 1644 (2006).

${ }^{17}$ L. A. Pinnaduwage, D. Yi, F. Tian, T. Thundat, and R. T. Lareau, Langmuir 20, 2690 (2004).

${ }^{18}$ G. Y. Chen, T. Thundat, E. A. Wachter, and R. J. Warmack, J. Appl. Phys. 77, 3618 (1995).

${ }^{19}$ R. I. Masel, Principles of Adsorption and Reaction on Solid Surfaces (Wiley, New York, 1996), p. 509. 